list represents decisions taken over many years by the Norwegian equivalent of the Committee on the Safety of Medicines. The belief is that a drug must be shown to be of acceptable efficacy and safety-and is "needed." If those conditions are not met the drug is kept out of the countryand certainly not made available only to those prepared to pay for it.

Several other objections may be raised to the government's proposals. In particular, they are likely to have their greatest impact on patients who are exempt from paying prescription charges-the poor, the unemployed, and the elderly. The changes will cause practical problems for patients in rural areas who have come to rely on their doctors to supply their drugs. If the remedy a patient wants is only available over the counter, will he or she have to travel many miles to the nearest pharmacy?

Either this scheme has been badly thought out with rejection of expert advice (mirroring the recent absurd comment from the DHSS that routine ultrasound was not safe for pregnant women ${ }^{4}$ ) or it is an attempt to "privatise" prescribing in Britain. Doctors should, we believe, reject it. If drugs are of dubious value or safety they should have their licence taken away by the Committee on Safety of Medicines (and not by diktat of the DHSS-despite Mr Kenneth Clarke's history of overruling his expert advisory committees). ${ }^{5}$ If too many products are in use the Committee on Safety of Medicines should be more rigorous in its scrutinies.
The $B M \mathcal{Y}$ has consistently argued that too many drugs are prescribed, with expensive, new, and fashionable preparations often being used irrationally (inappropriate use of antibiotics, histamine receptor antagonists, and steroids being three examples). ${ }^{6}$ More effective prescribing could save the NHS money and benefit patients at the same time. Hospital formularies have proved both effective and acceptable to hospital staff-and have been seen by them to improve the quality of prescribing while cutting costs. In some instances general practitioners have joined with their hospital colleagues in composing local formularies. Doctors and patients might be given incentives to take cost into account (such as a lower prescription charge for generic prescriptions). The BMA is asking for consultations with the DHSS (p 1468) and will suggest scrapping the concept of a limited list (rejected by Mr Patrick Jenkin when he was secretary of state) and looking for savings from generic prescribing and from removing anomalies in the exemptions from prescription charges. Many economies are possible; but whenever possible decisions on choice of drugs should be made locally by doctors in consultation or individually in the consulting room-not by the DHSS.

1 Anonymous. Secretary of State limits range of prescribable NHS drugs. BrMed f 1984;289: 1388-9. Feinmann I. Will you be prescribing less and your patients buying more? Medical Neves 1984 Nov $15: 29$

3 Bakke OM. Drug selection in a regulated society: the Norwegian experience. Hospital Formulary 1984;19:411-21.

4 Illman J. Anger over minister's warning on pregnancy scan "risks." Daily Mail 1984 Oct 22:3 5 Anonymous. Rejecting scientific advice [Editorial]. BrMed $\mathcal{J}$ 1982;284:142

6 Anonymous. Doctors and the drug industry [Editorial]. BrMed f 1983;286:579-80.

\title{
Treatment of pulmonary hypertension in chronic bronchitis and emphysema
}

Cor pulmonale is most often seen secondary to chronic bronchitis and emphysema-themselves most often induced by smoking. Increasingly claims are being made that patients can gain both haemodynamic and clinical benefits from treatment with vasodilators, calcium antagonists, or $\beta$ stimulants, and the marketing tactics of the drug manufacturers concerned have already attracted adverse comment. ${ }^{1}$ How far are the companies' claims justified?

The development of cor pulmonale in patients with chronic bronchitis and emphysema is an ominous sign: the five year mortality from the first episode is quoted as $60 \% .^{2}$ In cor pulmonale the right ventricle is not failing in the conventional sense, since cardiac output is normal or high ${ }^{3}$ - presumably as a compensatory measure to try to maintain oxygen delivery to the tissues. Indeed, the study from Japan by Kawakami $e t$ $a l$ showed that the mixed venous oxygen tension (generally a good guide to the state of tissue oxygenation) is an important prognostic factor in such patients. ${ }^{4}$ Many factors affect mixed venous oxygen tension, including lung function, the oxygen carrying capacity of the blood, and the cardiac output. The importance of oxygen delivery and the association with prognosis suggest that the mixed venous oxygen tension may be a better guide to the effectiveness of intervention than pulmonary pressures or resistances.

In treating patients with cor pulmonale efforts should first be made to improve lung function as much as possible. This usually means vigorous attempts at bronchodilatation. Occasionally there are worthwhile responses, as when chronic asthma presents as cor pulmonale. ${ }^{5}$ Smoking must be stopped to reduce the rapid rate of decline in lung function and to remove carboxyhaemoglobin, which reduces the body's ability to transport oxygen. Administration of oxygen would be expected to be helpful, and studies from both sides of the Atlantic have found a reduction in mortality in patients using oxygen for more than 15 hours. ${ }^{67}$ In these studies the administration of oxygen did not seem to reduce pulmonary artery pressure, but the further increases that might have been expected over the time of the study did not occur. Oxygen may, however, decrease the adaptive rise in cardiac output, and the practical difficulties and cost of such prolonged administration are such that enthusiasm has been maintained for alternative treatments.

Almitrine seems to increase ventilation by stimulating peripheral chemoreceptors and to have an additional effect in improving ventilation-perfusion relations. ${ }^{8}$ Treatment with almitrine has been shown to restore towards normal the blood concentrations of both oxygen and carbon dioxide in patients with chronic lung disease and to reduce desaturation episodes at night, which may be an important mechanism in thè production of cor pulmonale. ${ }^{10}$ However, worrying reports of an increase in pulmonary artery pressure with almitrine call for further careful evaluation. ${ }^{11}$

A number of vasodilators have been used in the treatment of pulmonary hypertension to try to reduce the pulmonary artery pressure and ease the work of the right side of the heart. In primary pulmonary hypertension the cardiac output is usually low and so the results (which are mixed) cannot necessarily be extended to pulmonary hypertension secondary to chronic lung disease. Many vasodilators have an effect on the pulmonary circulation but none-other than 
oxygen-selects this over the systemic circulation; so they may produce systemic hypotension, and this has indeed been a problem with hydralazine in several studies..$^{12} 13$

The calcium antagonist nifedipine is able to block hypoxic vasoconstriction in the pulmonary circulation. ${ }^{14}$ Both nifedipine and hydralazine have shown beneficial haemodynamic effects on secondary pulmonary hypertension in acute and short term studies in some hands. ${ }^{15-18}$ The consensus is that when these drugs are first used their effects should be monitored by invasive haemodynamic measurements to confirm effectiveness and help cope with adverse effects. Unfortunately, the changes in pulmonary artery pressure after eight weeks of treatment are not always predictable from the initial changes. ${ }^{17}$

Vasodilators which also act on the venous side, such as nitroglycerin (glyceryl trinitrate) and nitroprusside, may be harmful. ${ }^{18}$ The right ventricle probably needs a good filling pressure to keep up its adaptive response with a high cardiac output. Similarly, overenthusiastic use of diuretics may be harmful. It is worth tolerating a little oedema to give the heart a good head of steam. Digoxin, which might be expected to have a further positive inotropic effect, is not useful in cor pulmonale unless there is coexistent atrial fibrillation. ${ }^{19}$

Haemodynamic benefits at rest and on exercise have been shown from oral or parenteral $\beta$ stimulants, ${ }^{20-26}$ with little apparent difference from the choice among the selective agents. ${ }^{26}$ The action is thought to be a combination of positive inotropic effect and pulmonary vasodilatation. ${ }^{24}$ Haemodynamic effects have continued for six weeks with no problems except in patients with pre-existing extrasystoles. ${ }^{24}$ Invasive monitoring is not necessary; a response may be confirmed by radionuclide measurements of the ejection fraction, though this presents difficulties in the presence of overinflation. Carefully controlled long term studies will be necessary, however, before $\beta$ stimulation can be regarded as routine treatment for cor pulmonale. Possibly a further increase in cardiac output maintained over many months might even be deleterious.

Perhaps the $\beta$ stimulant responses give a clue to the future; what is needed may be a combined approach, improving oxygen carriage by giving oxygen or almitrine while dropping the pulmonary artery pressure with selective vasodilators and improving cardiac output with an inotrope.

At present, however, treatment should be to get the patient to stop smoking, reverse his airflow obstruction, go easy on the diuretics, and then consider long term low flow oxygen or possibly an oral $\beta$ stimulant. Meanwhile, clinicians should wait for a selective pulmonary vasodilator, more data on almitrine, and, most important, trials to show that early changes in haemodynamics continue and produce long term clinical improvement-and reduce mortality.

JOHN REES

Consultant Physician and Senior Lecturer,

Guy's Hospital Medical School,

London SE1 9RT

1 Crompton GK, Grant IWB. Pirbuterol. Lancet 1984;i:795

2 Ude AC, Howard P. Controlled oxygen therapy and pulmonary heart failure. Thorax 1971;26 $572-8$.

3 Richens JM, Howard P. Oedema in cor pulmonale. Clin Sci 1982;62:255-9

Kawakami Y, Kishi F, Yamamoto H, Miyamoto K. Relation of oxygen delivery, mixed venou oxygenation, and pulmonary hemodynamics to prognosis in chronic obstructive pulmonary disease. N Engl F Med 1983;308:1045-9.

5 Corris PA, Gibson GJ. Asthma presenting as cor pulmonale. Br Med f 1984;288:389-90. Nocturnal Oxygen Therapy Trial Group. Continuous or nocturnal oxygen therapy in hypoxemic chronic obstructive lung disease. Ann Intern Med 1980;93:391-8.

hedical Research Council Working Party. Long term domiciliary oxygen therapy in chronic hypoxic cor pulmonale complicating chronic bronchitis and emphysema. Lancet 1981 ;i:681-5. dastaing Y, Manier G, Varene N, Guanard H. Almitrine orale et distribution des rapports VA/Q
dans les bronchopneumopathie chroniques obstructives. Bull Eur Physiopathol Respir 1981;17 $917-32$.

9 Powles ACP, Tuxen DV, Pugsley SO, Sutton JR, Basalygo M, Campbell EJM. The effect of almitrine on sleep hypoxemia in patients with chronic airflow limitation. Am Rev Respir Dis 1984;129:A66.
10 Douglas NJ, Calverley PMA, Leggett RJE, Brash HM, Flenley DC, Bezirova V. Transient hypoxaemia during sleep in chronic bronchitis and emphysema. Lancet 1979; ;:1-4.

Dall WL, Polu JM, Sadoul P. The pulmonary haemodynamic effects of almitrine infusion in man with chronic hypercapnia. Clin Sci 1983;64:25-31.

Per $M$, Greenberg B, Massie B, Dash $H$. Deleterious effects of hydralazine in patients with

upi-Herrera $E$, Seoane $M$, Verdejo $J$. Hemodynamic effect of hydralazine in advanced, stable chronic obstructive pulmonary disease with cor pulmonale. Chest 1984;85:156-63.

4 Simonneau G, Escourrou P, Duroux P, Lockhart A. Inhibition of hypoxic pulmonary vasoconstriction by nifedipine. $N$ Engl f Med 1981;304:1582-5.

Rubin LJ, Peter RH. Hemodynamics at rest and during exercise after oral hydralazine in patients with cor pulmonale. Am $\mathcal{J}$ Cardiol 1981;47:116-22.

Rubin LJ, Handel F, Peter RH. The effects of oral hydralazine on right ventricular end-diastolic pressure in patients with right ventricular failure. Circulation 1982;65:1369-73.

17 Sturani C, Bassein L, Schiavina M, Gurella G. Oral nifedipine in chronic cor pulmonale secondary to severe chronic obstructive pulmonary disease (COPD). Short and long-term hemodynamic

8 Brent BN, Berger HJ, Matthay RA, Mahler D, Pytlik L, Zaret BL. Contrasting acute effects of vasodilators (nitroglycerin, nitroprusside and hydralazine) on right ventricular performance in radionuclide-hemodynamic study. Am 7 Cardiol 1983;51:1682-9.

Brown SE, Pakron FJ, Milne N, et al. Effects of digoxin on exercise capacity and right ventricula function during exercise in chronic airflow obstruction. Chest 1984;85:187-91

20 Lockhart A, Lissac J, Salmon D, Zappacosta C, Benismail M. Effects of isoproterenol on the pulmonary circulation in obstructive airways disease. Clin Sci 1967;32:177-8 .

Stockley RA, Finnegan R, Bishop JM. Effect of intravenous terbutaline on arterial blood gas tensions, ventilation, and pulmonary circulation in patients with chronic bronchitis and cor pulmonale. Thorax 1977;32:601-5.

2 Teule GJJ, Majid PA. Haemodynamic effects of terbutaline in chronic obstructive airways disease. Thorax 1980;35:536-42.

Brent BN, Mahler D, Berger HJ, Matthay RA, Pytlik L, Zaret BL. Augmentation of right ventricular performance in chronic obstructive pulmonary disease by terbutaline: a combined MacNee W, Wathen CG, Hannan WJ. Flenley DC Cardiol 1982;50:313-9. nitroprusside on pulmonary haemodynamics in hypoxic cor pulmonale. Br Med $\mathcal{J}$ 1983;287: $1169-72$.

25 Peacock A, Busst C, Dawkins K, Denison DM. Response of pulmonary circulation to oral pirbuterol in chronic airflow obstruction. Br Med $\mathcal{J} 1983 ; 287: 1178-80$

26 Winter RJD, Langford JA, Rudd RM. Effects of oral and inhaled salbutamol and oral pirbutero on right and left ventricular function in chronic bronchitis. $\mathrm{BrMed} \mathcal{F} 1984 ; 288: 824-5$.

\section{Help for the child who is sexually abused}

Sadly, not only should we caution our children against talking to strangers; we should think about protecting them from father, uncles, grandfathers, and even mother. Sexual abuse of children is now known usually to take place within the family or among family acquaintances. ${ }^{1}$ In a series of 56 children referred to the Hospital for Sick Children, London, for treatment only one of the assailants was totally unknown to the child. ${ }^{2}$ In a larger series in Britain three quarters of the assailants were known to the child, with $43 \%$ relatives and $31 \%$ family acquaintances; of the relatives, $48 \%$ were fathers, $28 \%$ stepfathers, and even $5 \%$ mothers; $7 \%$ of the victims were boys.' Similar figures have been reported from the United States. ${ }^{3}$ Incidents may range from kissing and touching to full sexual intercourse; indeed, one of the problems for the doctor is differentiating caring and nurturing from sexual exploitation. ${ }^{4}$ It would be a tragedy if publicity about child sexual abuse deterred parents from physical expression of their affection for their children.

In the distant past incest was considered to be immoral rather than criminal behaviour and so was the province of the church: until 1908 in England it was punished in ecclesiastical courts. ${ }^{5}$ Only in 1980 was sexual abuse included in the Department of Health and Social Security's statistics in the definition of child abuse, and reported cases are still probably only the tip of the iceberg. At least three children in every 1000 in Britain will be recognised by a professional as having been sexually abused in some way during childhood, but the true incidence is almost impossible to ascertain since there is a conspiracy of silence, certainly by the family and often by professionals who come to know what is going on. ${ }^{6}$ The doctor who suspects incest is in a dilemma: he may consider that the damage to the child will be worse if he reports the case to the police-and sadly his fears may be accurate. Society's first thought is to punish the offender, by removing him to prison where he can do no harm; but usually no effort 